\title{
High-strength, healable, supramolecular polymer nanocomposites
}

Article

Supplemental Material

Fox, J., Wie, J., Greenland, B., Burattini, S., Hayes, W., Colquhoun, H., Mackay, M. and Rowan, S. (2012) Highstrength, healable, supramolecular polymer nanocomposites. Journal of the American Chemical Society, 134 (11). pp. 53625368. ISSN 0002-7863 doi: https://doi.org/10.1021/ja300050x Available at https://centaur.reading.ac.uk/27638/

It is advisable to refer to the publisher's version if you intend to cite from the work. See Guidance on citing.

Published version at: http://pubs.acs.org/doi/abs/10.1021/ja300050x

To link to this article DOI: http://dx.doi.org/10.1021/ja300050x

Publisher: American Chemical Society

All outputs in CentAUR are protected by Intellectual Property Rights law, including copyright law. Copyright and IPR is retained by the creators or other copyright holders. Terms and conditions for use of this material are defined in the End User Agreement.

\section{www.reading.ac.uk/centaur}

\section{CentAUR}

Central Archive at the University of Reading 
Reading's research outputs online 


\section{Supporting Information}

\section{High-Strength, Healable, Supramolecular Polymer Nanocomposites}

Justin Fox, ${ }^{1}$ Jeong J. Wie, ${ }^{2}$ Barnaby W. Greenland, ${ }^{3}$ Stefano Burattini, ${ }^{3}$ Wayne Hayes, ${ }^{3}$ Howard M. Colquhoun, ${ }^{3}$ Michael E. Mackay, ${ }^{2,4}$ and Stuart J. Rowan, ${ }^{1 *}$

${ }^{1}$ Department of Macromolecular Science and Engineering, 2100 Adelbert Road, Kent Hale Smith Building, Cleveland, Ohio 44106, USA.

${ }^{2}$ Department of Chemical Engineering, University of Delaware, 150 Academy St., Newark, DE, 19716, USA.

${ }^{3}$ Department of Chemistry, University of Reading, Whiteknights, Reading, RG6 6AD, UK.

${ }^{4}$ Department of Materials Science \& Engineering, University of Delaware, 201 DuPont Hall, Newark, DE, 19716, USA.

\section{Contents}

$\begin{array}{ll}\text { Figure S1: Isolation and characterization of } \mathrm{CNCs} & \mathrm{S} 2\end{array}$

$\begin{array}{ll}\text { Figure S2: Conductometric titration of CNCs } & \text { S3 }\end{array}$

$\begin{array}{ll}\text { Figure S3: Thermogravimetric analysis of nanocomposites } & \text { S3 }\end{array}$

$\begin{array}{ll}\text { Figure S4: Effects of compression molding } & \text { S4 }\end{array}$

Figure S5: Images of $20 \mathrm{wt} . \%$ nanocomposite films $\quad$ S4

$\begin{array}{ll}\text { Figure S6: Rheology data } & \text { S5 }\end{array}$

$\begin{array}{ll}\text { Figure S7: Rheology recovery data } & \text { S6 }\end{array}$

$\begin{array}{ll}\text { Figure S8: Rheology deformation process and rate of recovery } & \text { S7 }\end{array}$

$\begin{array}{lr}\text { Figure S9: Environmental scanning electron microscopy } & \text { S8 }\end{array}$

Figure S10: SEM of the fracture surface of the $7.5 \mathrm{wt} \%$ composite $\quad$ S9

$\begin{array}{ll}\text { References to Supporting Information } & \text { S9 }\end{array}$ 


\section{Isolation and characterization of CNCs}

Tunicates (Styela clava) were collected from Snug Harbor Marina (Wakefield, RI) and processed into cellulose nanocrystals (CNCs) as previously described. ${ }^{1}$ TEM images of CNCs were acquired using a JEOL 1200EX Transmission Electron Microscope. All samples were prepared on carbon-coated copper grids using a standard uranyl acetate negative staining method. ${ }^{2}$ Conductometric titrations were conducted on an Accumet AR50 Dual Channel $\mathrm{pH} / \mathrm{Ion} /$ Conductivity Meter using established techniques. ${ }^{3}$

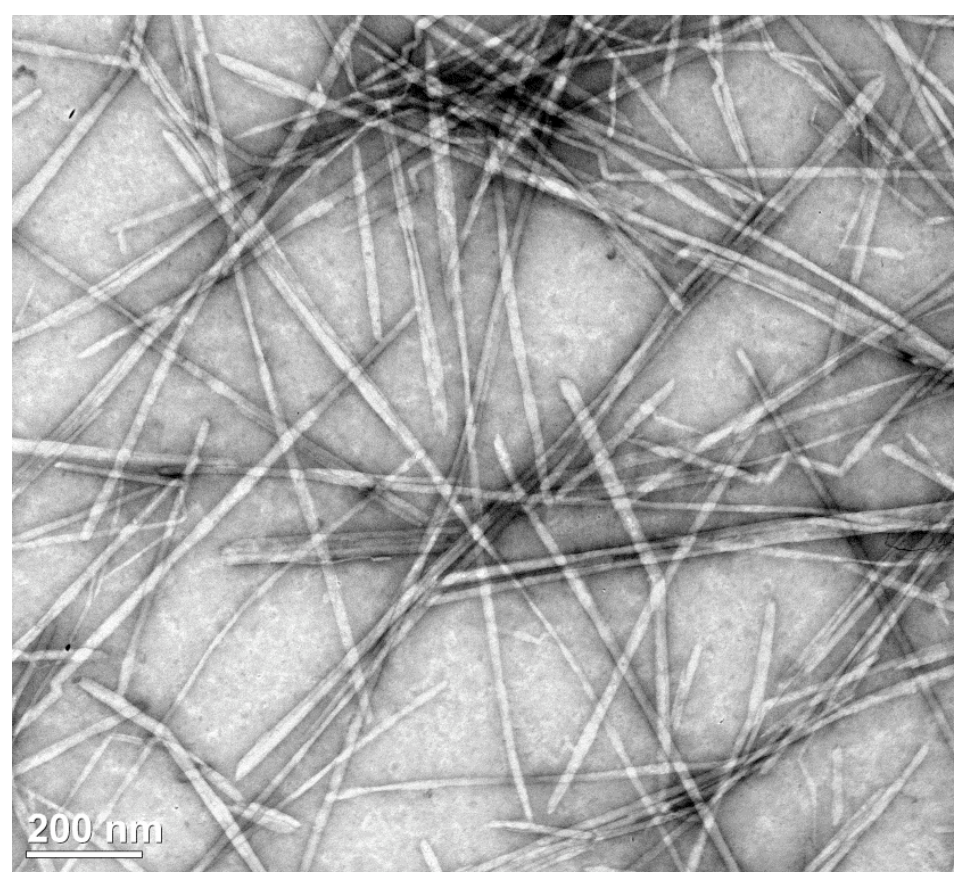

Figure S1. Transmission electron microscopy of tunicate whiskers, as isolated from tunicate mantles. 


\section{Conductometric titration of CNCs}

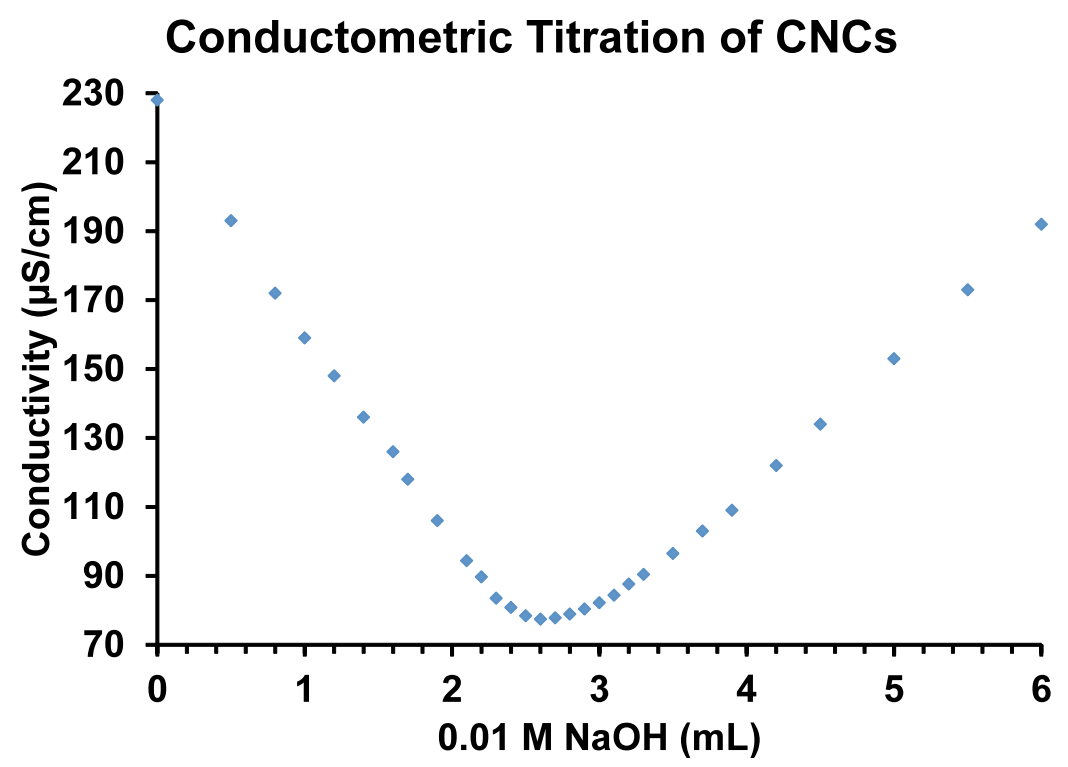

Figure S2. Conductometric Titration of CNCs. Typical curve representing conductometric titration of $50 \mathrm{mg}$ of CNCs suspended in approx. $50 \mathrm{~mL}$ of deionized $\mathrm{H}_{2} \mathrm{O}$. Three titrations are performed and averaged to yield sulfate charge density of $130 \mathrm{mmol} / \mathrm{kg}$ for the CNCs used in this study.

\section{Thermogravimetric analysis}

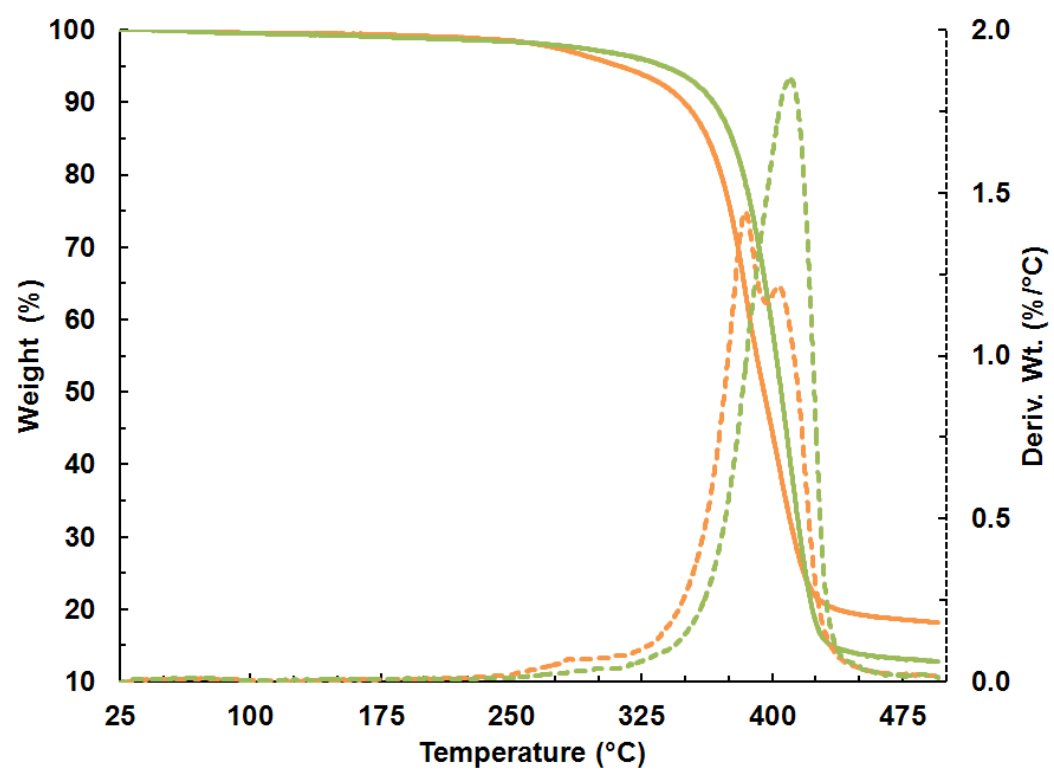

Figure S3. TGA of typical nanocomposite. Typical weight loss curves (solid lines) for dried nanocomposites of $5 \mathrm{wt} \%$ CNC (green) and $20 \mathrm{wt} \%$ CNC (orange). Derivative weight loss given as green and orange dashed lines (for 5 and $20 \mathrm{wt} \%$, respectively) and correspond with dashed axis on right. 


\section{Effects of Compression Molding}

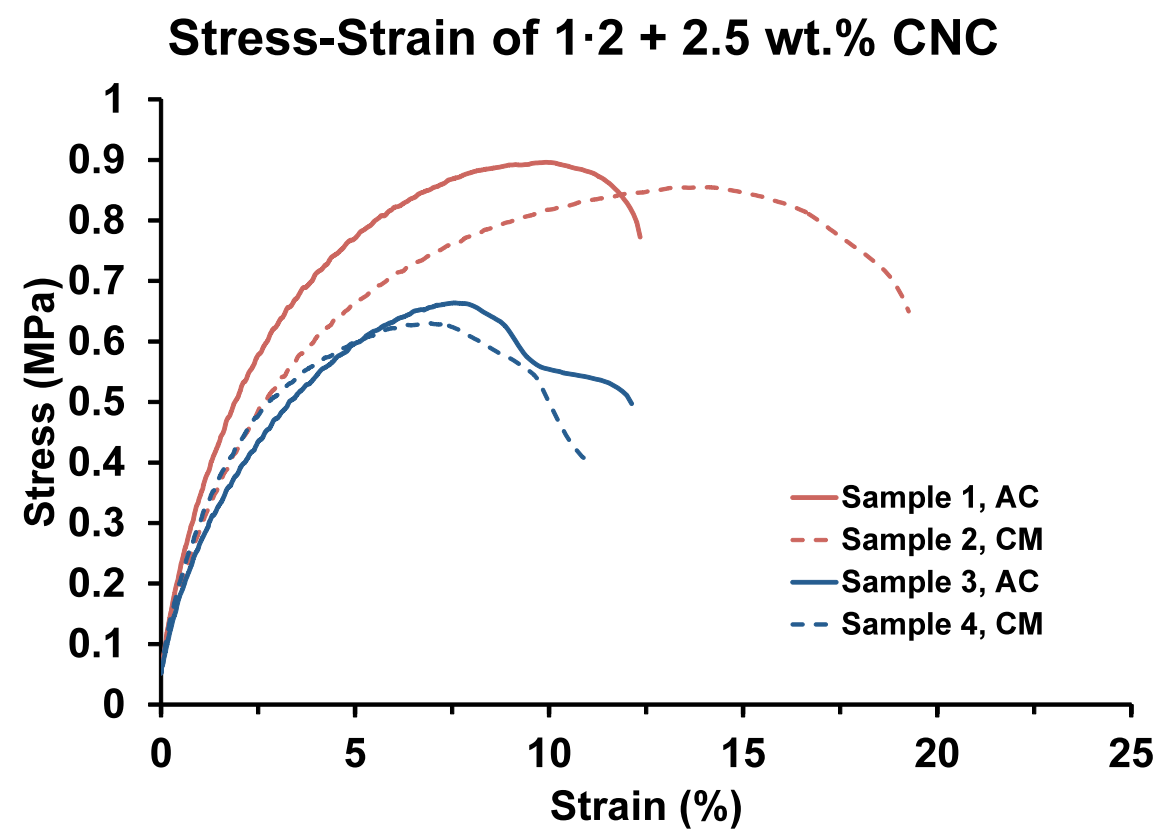

Figure S4. Stress-Strain curves for typical nanocomposites. Samples of $\mathbf{1} \cdot \mathbf{2}+2.50 \mathrm{wt} . \% \mathrm{CNC}$ were subject to tensile testing in their as-cast state (AC, solid lines) and after compression molding at $85{ }^{\circ} \mathrm{C}$ under $200 \mathrm{kPa}$ for 5 minutes (CM, dashed lines). Samples represented by lines of the same color were cut from adjacent areas of film. Compression molded samples have more consistent tensile moduli, indicated by the near superposition of the data representing Samples 2 and 4 below $2.5 \%$ strain.

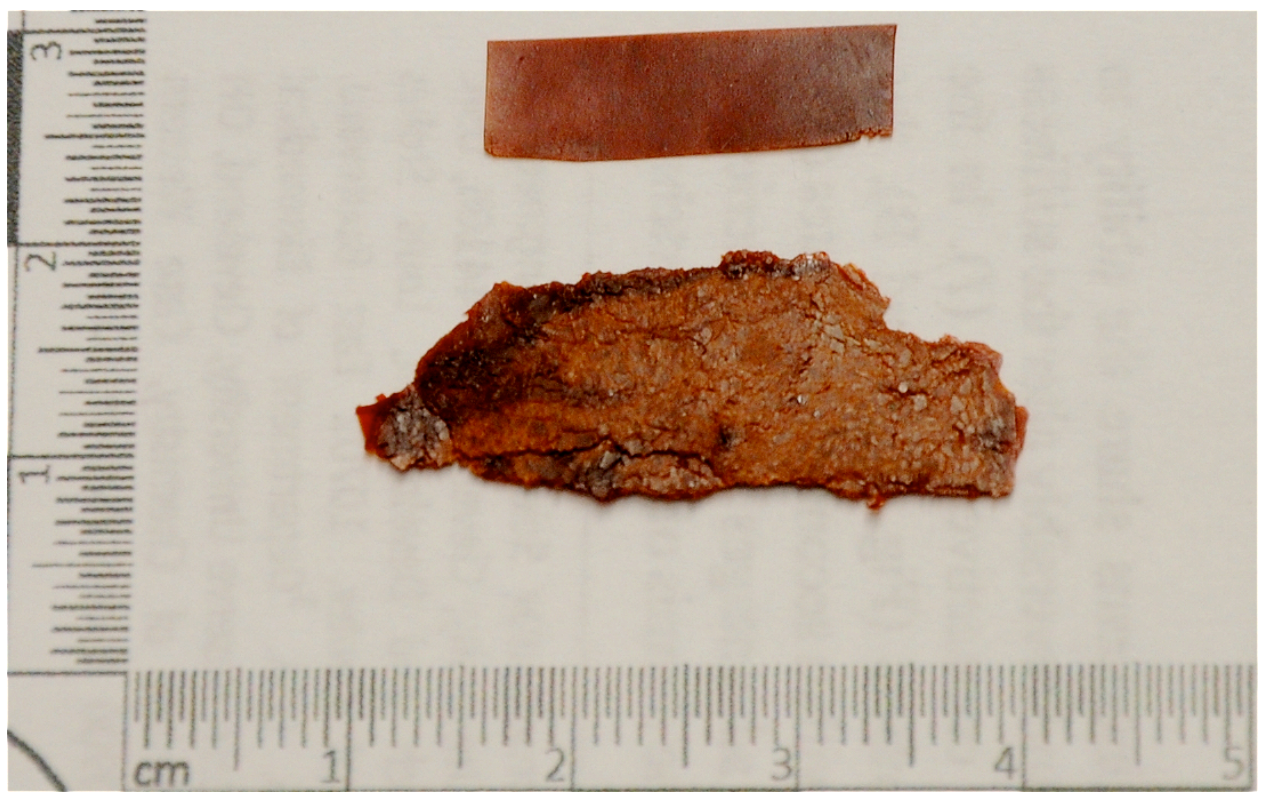

Figure S5. Image of $20 \mathrm{wt} . \%$ nanocomposite films as cast from solution (top sample) and after melt processing at $85^{\circ} \mathrm{C}$ and $200 \mathrm{kPa}$ (bottom sample). 


\section{Rheology Data}
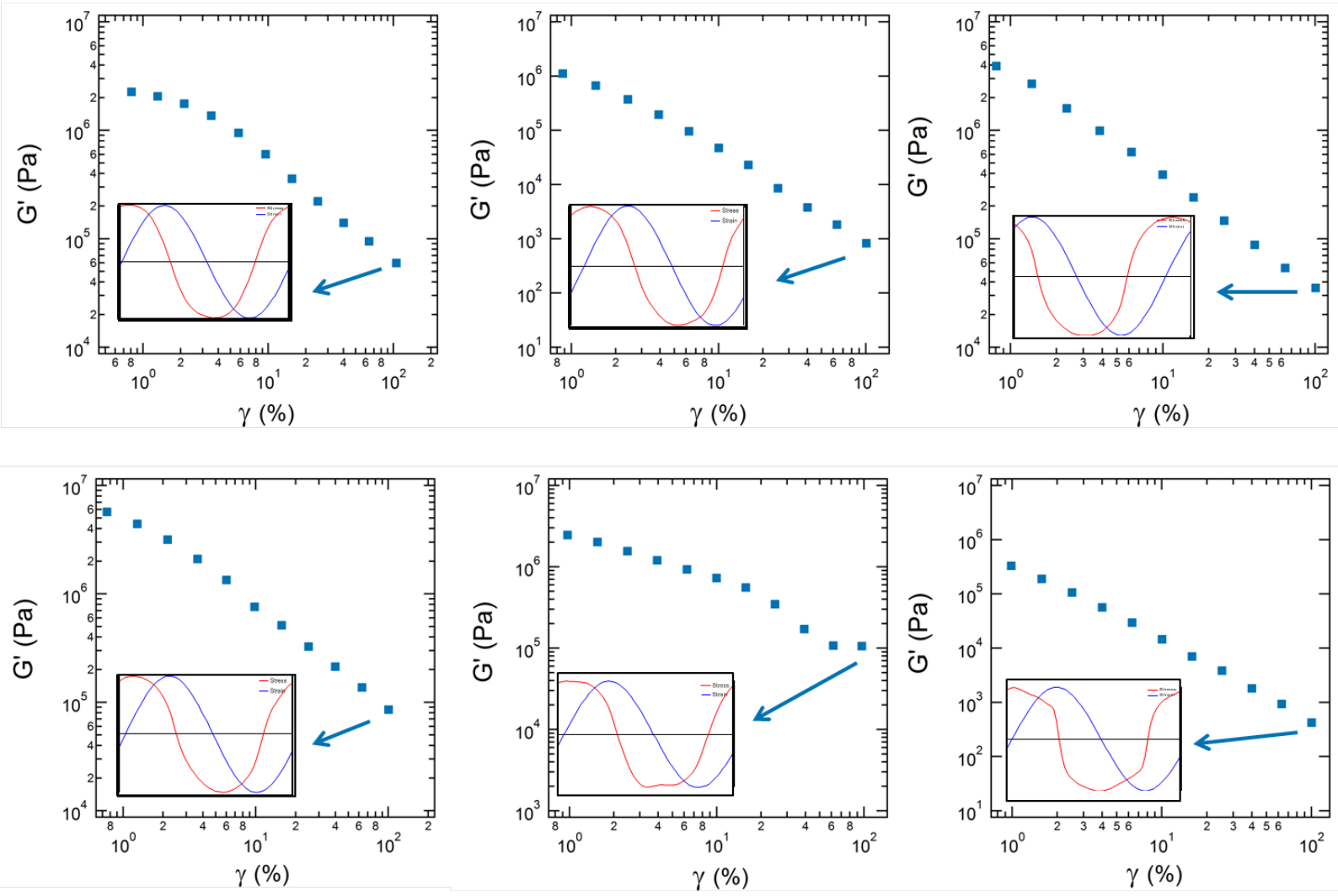

Figure S6. Deformation process for 1.25 wt. $\%, 2.50$ wt. $\%$ and 5.00 wt.\% (top left to right) and 7.50 wt. $\%, 10.00$ wt. $\%$ and 20.00 (bottom left to right) at $65^{\circ} \mathrm{C}$. Frequency of $\omega=100$ $\mathrm{rad} / \mathrm{s}$ was applied to $1.25 \mathrm{wt} . \%$ and $2.50 \mathrm{wt} \%$ nanocomposites and $\omega=10 \mathrm{rad} / \mathrm{s} \mathrm{was}$ applied to 5.00 wt. $\%, 7.50$ wt. $\%, 10.00$ wt.\% and 20.00 wt.\% nanocomposites. 

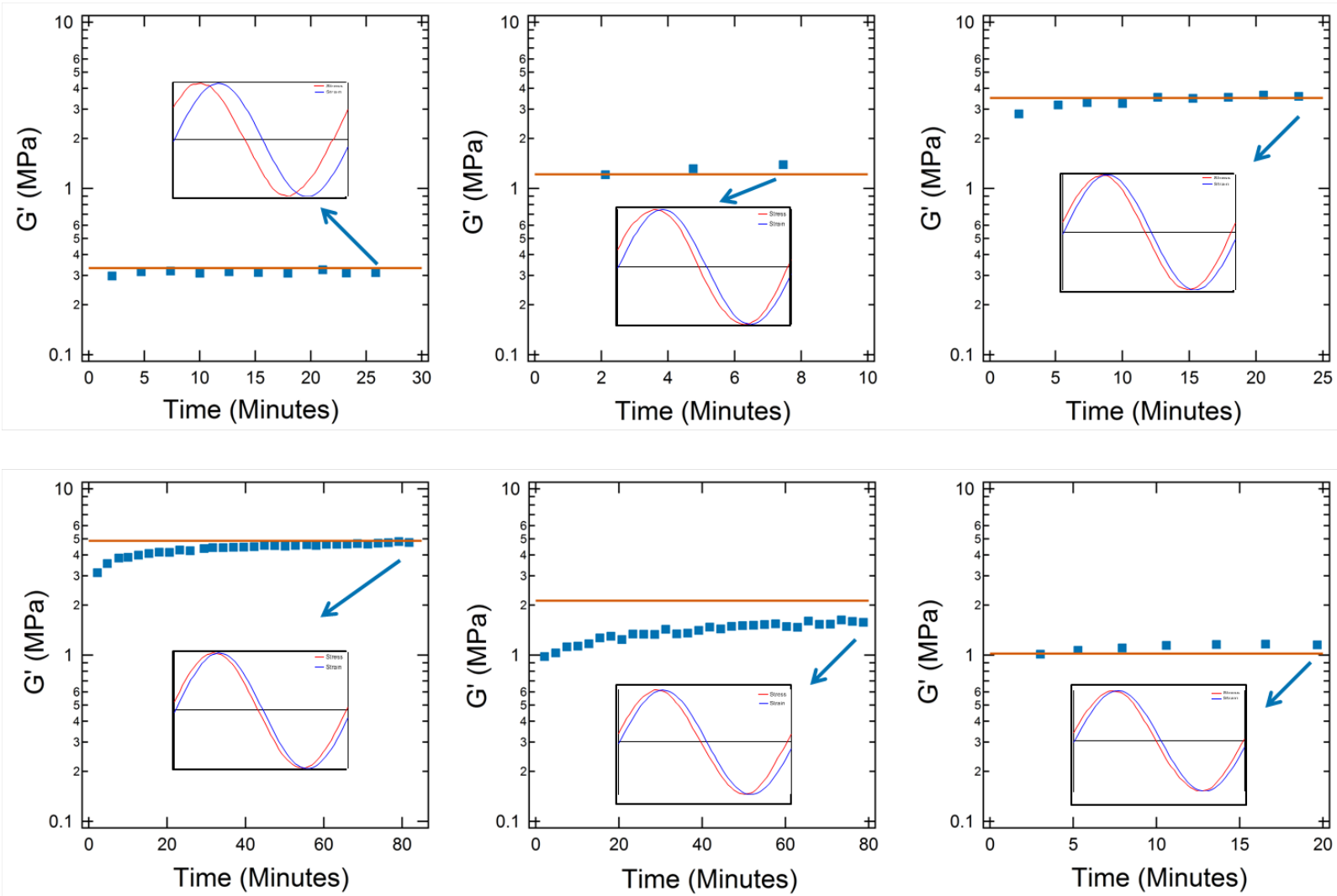

Figure S7. Rate of recovery $(\omega=0.1 \mathrm{rad} / \mathrm{s}, \gamma=0.1 \%)$ of $1.25 \mathrm{wt.} \%, 2.50 \mathrm{wt.} \%, 5.00 \mathrm{wt.} \%$, (top left to right) 7.50 wt.\%, 10.00 wt.\% and 20.00 wt.\% (bottom left to right) nanocomposites at $65^{\circ} \mathrm{C}$. The initial modulus (red line) was measured at $65^{\circ} \mathrm{C}$ at low frequency and strain $(\omega=0.1 \mathrm{rad} / \mathrm{s}, \gamma=0.1 \%)$. The samples were then broken using a strain sweep as shown in Figure S6. Recovery of the shear storage modulus was then monitored at $65^{\circ} \mathrm{C}$ over a period of time $(\omega=0.1 \mathrm{rad} / \mathrm{s}, \gamma=0.1 \%)$ 

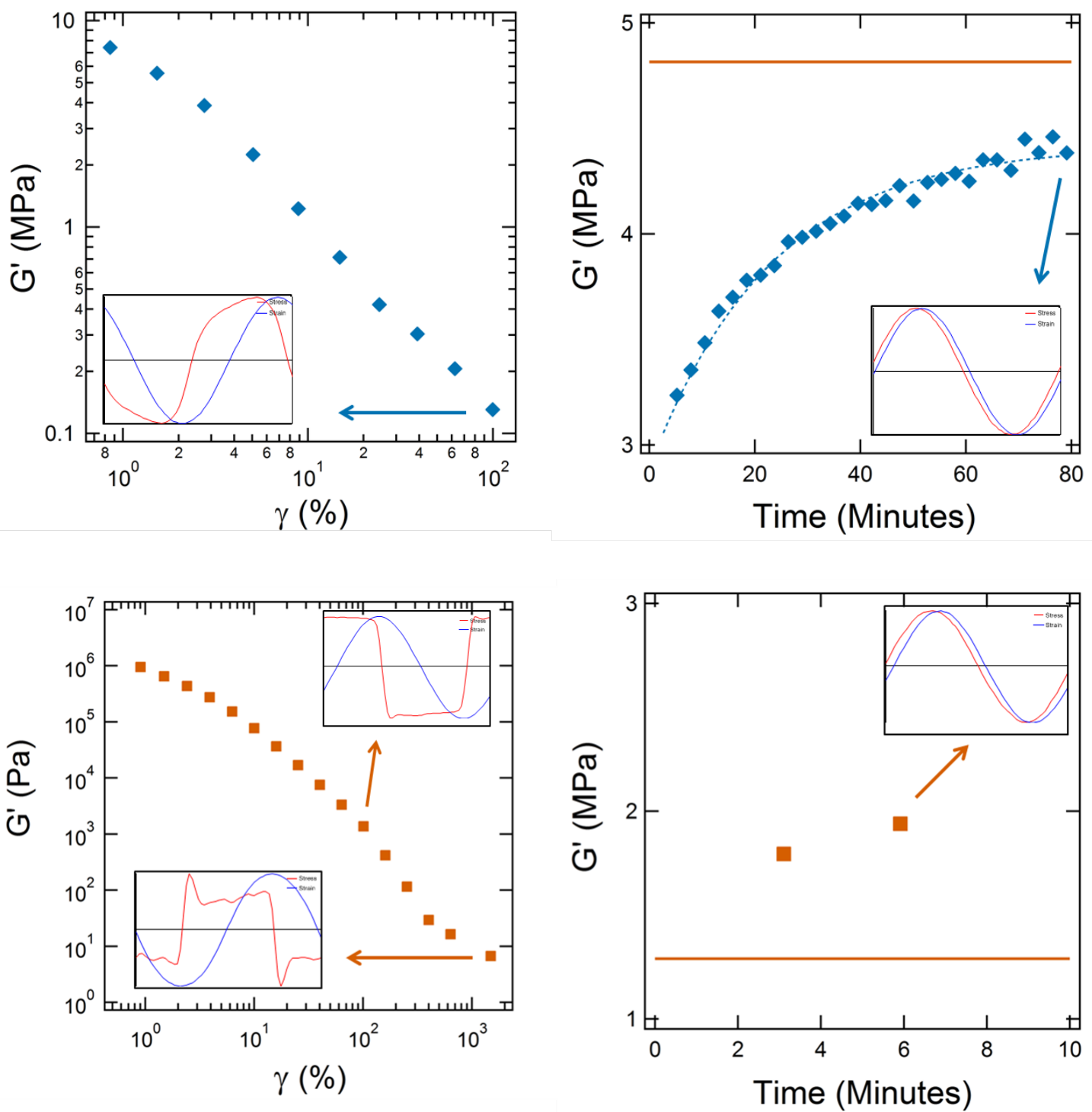

Figure S8. Deformation process, left, $(\omega=100 \mathrm{rad} / \mathrm{s})$ and rate of recovery, right, $(\omega=0.1$ $\mathrm{rad} / \mathrm{s}, \gamma=0.1 \%$ of $7.50 \mathrm{wt} . \%$ (top) and $20.00 \mathrm{wt} \%$ (bottom) nanocomposite at $65^{\circ} \mathrm{C}$. The initial modulus (red line) was measured at $65^{\circ} \mathrm{C}$ at low frequency and strain $(\omega=0.1 \mathrm{rad} / \mathrm{s}, \gamma=0.1 \%)$. The sample was then broken using a strain sweep $(\omega=100 \mathrm{rad} / \mathrm{s})$. Recovery of the shear storage modulus was then monitored at $65^{\circ} \mathrm{C}$ over a period of time $(\omega=0.1 \mathrm{rad} / \mathrm{s}, \gamma=0.1 \%)$

As previously shown in Figure S7, after experiencing the deformation process at a frequency of $10 \mathrm{rad} / \mathrm{s}$, the $7.50 \mathrm{wt} \%$ nanocomposite fully recovered its initial modulus at the 80 minute time mark. However, the same sample deformed at $100 \mathrm{rad} / \mathrm{s}$ only recovered about $90 \%$ of the initial modulus at the same time mark as shown in Figure S8. Non-linear and linear stress-strain responses were observed for the deformed and the self-healed nanocomposites, respectively. Deformed $20.00 \mathrm{wt} . \%$ nanocomposite showed the highly non-linear stress-strain response at 100 $\mathrm{rad} / \mathrm{s}$ and $1000 \%$ of strain. The linear stress-strain response was recovered only within 3 minutes of self-healing process at $65{ }^{\circ} \mathrm{C}$. The recovered modulus was even higher than the initial modulus, once again providing evidence for phase separation of $20.00 \mathrm{wt} . \%$ nanocomposite. It 
appears that high shear and strain helped the mixing of phase-separated whiskers in the polymer matrix and increased storage modulus. After the self-healing process, all the nanocomposites studied recovered the linear stress-strain responses.

\section{Electron microscopy studies}
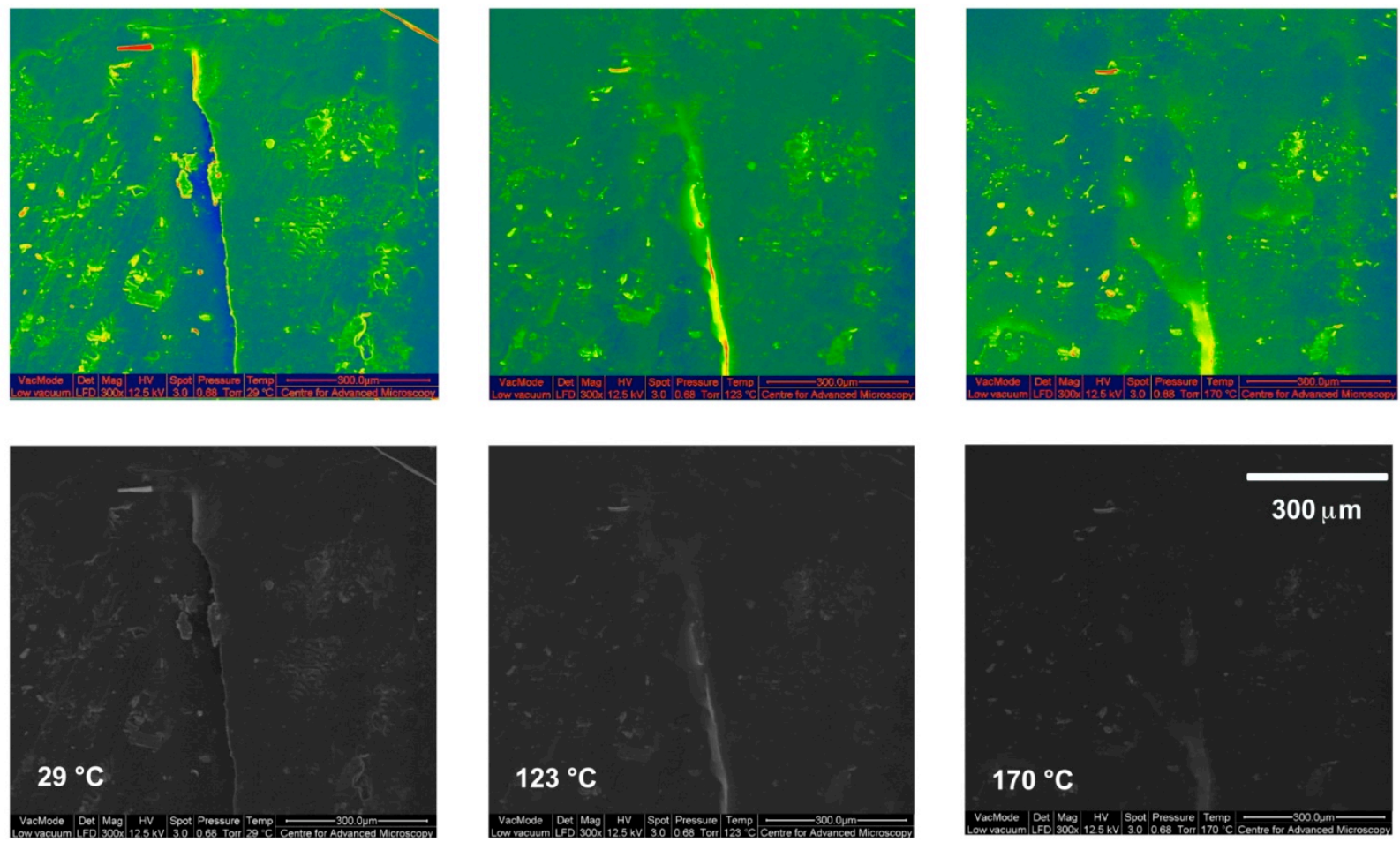

Figure S9. Healing of the $1.25 w t \%$ CNC composite. The sample was fractured and then heated to $200{ }^{\circ} \mathrm{C}$, at $5{ }^{\circ} \mathrm{C} \mathrm{min}^{-1}$, in an environmental scanning electron microscope (FEI Quanta FEG $600)$. The images show progressive healing of the sample between room temperature and 170 ${ }^{\circ} \mathrm{C}$. Original micrographs are reproduced below, with corresponding false-color images above. 


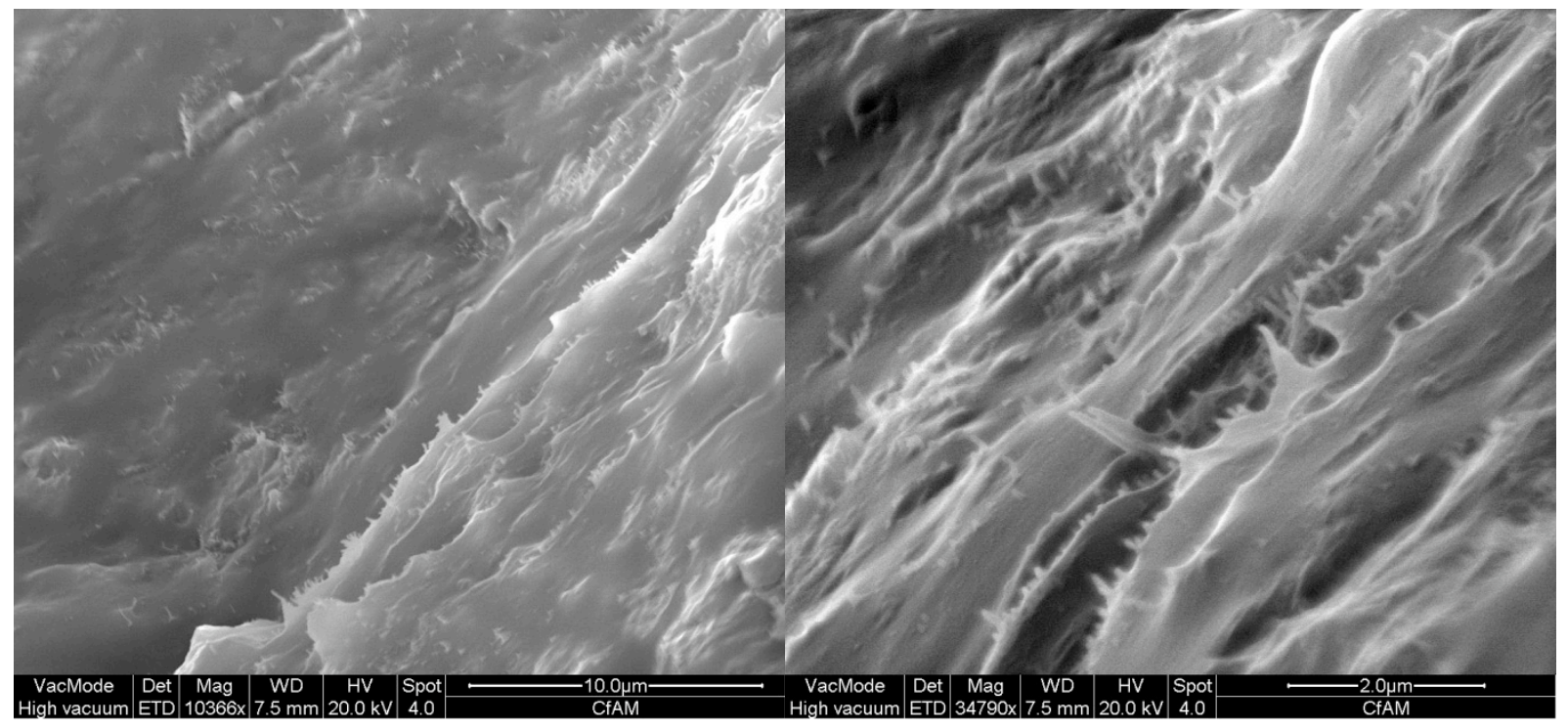

Figure S10: SEM images of the fracture surface of the $7.5 \mathrm{wt} \%$ composite. SEM images were acquired on a FEI Quanta field-emission scanning electron microscope at an accelerating voltage of $20 \mathrm{kV}$.

\section{References}

\footnotetext{
${ }^{1}$ van den Berg, O.; Capadona, J. R.; Weder, C. Biomacromolecules 2007, 8, 1353-1357.

${ }^{2}$ le Cam, E.; Frechon, D.; Barray, M.; Fourcade, A.; Delain, E. Proc. Natl. Acad. Sci. USA 1994, 91, 11816-11820.

${ }^{3}$ Rusli, R.; Shanmuganathan, K.; Rowan, S. J.; Weder, C.; Eichhorn, S. J. Biomacromolecules, 2011, 12, 1363-1369.
} 